\title{
Effect of Preparation Conditions on Morphology, Drug Content and Release Profiles of Poly(hydroxybutyrate) Microparticles Containing Piroxicam
}

\author{
G. C. Bazzo, ${ }^{a}$ E. Lemos-Senna, ${ }^{b}$ M. C. Gonçalves ${ }^{c}$ and A. T. N. Pires ${ }^{*, a}$
}

${ }^{a}$ Grupo de Estudos em Materiais Poliméricos, POLIMAT, Departamento de Química, Universidade Federal de Santa Catarina, Campus Universitário, Trindade, 88040-900 Florianópolis-SC, Brazil

${ }^{b}$ Laboratório de Farmacotécnica, Departamento de Ciências Farmacêuticas, Universidade Federal de Santa Catarina, Campus Universitário, Trindade, 88040-900 Florianópolis-SC, Brazil

'Instituto de Química, Universidade Estadual de Campinas, 13084-862 Campinas-SP, Brazil

No presente estudo foram preparadas micropartículas de poli(hidroxibutirato) contendo piroxicam pela técnica de emulsão-evaporação do solvente. A influência de alguns parâmetros do processo sobre a eficiência de encapsulação do fármaco foi avaliada por meio de um planejamento fatorial do tipo $2^{3}$. A eficiência de encapsulação do piroxicam variou de 5,5 a 89,8\%. Micropartículas ocas e irregulares, contendo cristais de fármaco na superfície, foram obtidas quando se utilizou $5 \mathrm{~mL}$ de clorofórmio como fase interna da emulsão. Com o ensaio de liberação in vitro evidenciouse que, após $8 \mathrm{~h}$, todo o fármaco havia sido liberado para o meio. Micropartículas esféricas com superfície externa rugosa e porosa foram obtidas quando se utilizou $20 \mathrm{~mL}$ de diclorometano como fase interna e adicionou-se isopropanol à fase externa da emulsão. Essas microesferas foram capazes de controlar a liberação do piroxicam durante $50 \mathrm{~h}$. Os resultados obtidos demonstraram que é possível obter micropartículas com características específicas pela otimização das condições empregadas no processo de encapsulação.

In this study, poly(hydroxybutyrate) microparticles containing piroxicam were prepared by the oil-in-water emulsion-solvent evaporation method. The effects of some process conditions on drug content were determined using a $2^{3}$ factorial design. The piroxicam loading efficiency varied from 5.5 to $89.8 \%$. Hollow and irregular microparticles with drug crystals on their surfaces were obtained when $5 \mathrm{~mL}$ of chloroform was used as the internal phase. In the release study, all of the piroxicam was released to the dissolution medium (phosphate buffer $\mathrm{pH} 7.4$ ) after $8 \mathrm{~h}$. Small spherical microspheres with a rough and porous polymeric matrix were obtained when 20 $\mathrm{mL}$ of dichloromethane was used as the internal phase and isopropanol was added to the external aqueous phase. These microspheres controlled the piroxicam release for approximately $50 \mathrm{~h}$. The results demonstrated that it is possible to obtain microparticles with specific characteristics by the optimization of the process conditions.

Keywords: poly(hydroxybutyrate), microparticles, piroxicam, controlled release

\section{Introduction}

The development of new drug delivery systems is considered an important approach to obtain a desired pharmacological effect in an efficient manner, which is preferable to altering the chemical nature of the drug. This approach can be applied to prolong drug release and improve therapeutic efficacy, safety and patient compliance. Several polymers have been used to obtain

*e-mail: pires@qmc.ufsc.br drug delivery systems; however, aliphatic polyesters are by far the most preferable ones, due to their biodegradation and biocompatibility characteristics. In particular, the polyhydroxyalkanoates (PHAs) have received special attention as promising biomaterials for the preparation of microparticulate drug carriers. ${ }^{1-2}$ The first and most reported PHA is poly(3-hydroxybutyrate) [PHB], the degradation of which leads to the formation of 3-hydroxybutiric acid, which is one of the three endogenous ketones produced by a process known as ketogenesis. Also, low molecular weight PHBs, complexed to other macromolecules, are 
able to pervade aqueous as well as hydrophobic regions of the cells and, thus, they can be found in cytoplasm and intracellular fluids, as well as in membranes and lipoproteins. Furthermore, linear or cyclic oligomers and/ or derivatives of 3-hydroxyacids can be administrated orally in order to increase the blood ketone levels as a nutritional or dietary supplement, which is useful for seizure control, metabolic disease control, increasing cardiac efficiency, and the treatment of diabetes and other disorders. Thus, it is assumed that PHB, along with its oligomers and monomers, is not toxic to cells, and can even provide some therapeutic or nutritional benefits. ${ }^{3}$

Several techniques can be used to prepare polymeric microparticles. The choice of the technique depends on the characteristics of the polymer, the drug and the intended use. The emulsion-solvent evaporation method is the one most frequently used to prepare microspheres. In this process, the drug and the polymer are dissolved in an organic phase, which is emulsified in an aqueous phase containing a stabilizing agent, under stirring. The organic solvent diffuses into the aqueous phase and it evaporates at the water/air interface. The microparticles are then washed, collected and dried. ${ }^{4-6}$ The characteristics of microparticles obtained through this technique are affected by process parameters such as solvent, temperature, volume ratio of disperse-continuous phase, type and concentration of the emulsifier, drug/polymer ratio and stirring rate. ${ }^{7}$ The solvent removal kinetics can affect the physicochemical properties of the microparticles, in particular the surface morphology and porosity, which in turn affects the rate of drug release.

In this study, the processing conditions that affect the characteristics of the PHB microparticles were determined in order to obtain microparticles with high piroxicam (PXC) loading efficiencies and the potential to control drug release. Piroxicam is extensively used in the treatment of osteoarthritis and rheumatoid arthritis in elderly patients, but as with other nonsteroidal anti-inflammatory drugs (NSAIDs), PXC is well known for its gastrotoxic and duodenotoxic effects when used orally. ${ }^{8}$ Thus, the incorporation of this drug in PHB microparticles offers a means not only to control the drug release, but also to minimize or eliminate the local side effects. A reduction in the oral side effects of NSAIDs can be also accomplished through the injection of the drug at the site of inflammation (intraarticular, for example). ${ }^{9}$ However, the short synovial half-life of NSAIDs would require frequent injections to maintain therapeutic levels. ${ }^{10}$ Therefore, biodegradable and biocompatible PHB microparticles show potential application in the delivery of piroxicam, by oral or parenteral route.

\section{Experimental}

Materials

Poly(hydroxybutyrate) $\left(\mathrm{M}_{\mathrm{n}}=312,800 \mathrm{~g} \mathrm{~mol}^{-1}\right.$ and polydispersity degree of 1.23 , determined by gel permeation chromatography) was kindly supplied by PHB Industrial S.A. (Serrana, São Paulo, Brazil). Piroxicam was purchased from Deg Imp. Produtos Químicos (São Paulo, Brazil) and poly(vinyl alcohol) $\left(\mathrm{M}_{\mathrm{n}}=92,000 \mathrm{~g} \mathrm{~mol}^{-1}\right.$, according to information supplied by the manufacturer) from Vetec (Rio de Janeiro, Brazil). Isopropanol, dichloromethane and chloroform were acquired from Nuclear, Brazil; Tedia Company, USA and Vetec, Brazil, respectively. All chemicals were used without further purification.

\section{Preparation of microparticles}

PHB/PXC microparticles were prepared by the oilin-water emulsion-solvent evaporation technique. The polymer $(500 \mathrm{mg})$ and the drug $(200 \mathrm{mg})$ were dissolved in an organic solvent (internal phase) and then emulsified in $200 \mathrm{~mL}$ of an aqueous phase containing $0.15 \%(\mathrm{~m} / \mathrm{v})$ of poly(vinyl alcohol) [PVA] as stabilizer (external phase). When necessary, $6 \%(\mathrm{v} / \mathrm{v})$ of isopropanol was added to the aqueous phase. The resulting emulsion was stirred at $700 \mathrm{rpm}$, at room temperature, until the evaporation of the organic solvent. The microparticles were washed with distilled water, dried and stored under vacuum at room temperature. In order to determine the effect of some process conditions on the efficiency of drug loading, the experiments were performed using a $2^{3}$ factorial design. The independent variables analyzed were: the type of the organic solvent of the internal phase, the volume of the organic solvent and the addition of isopropanol to the aqueous external phase. Table 1 shows the independent variables and their levels investigated in the preparation of the microspheres. The data were evaluated by analysis of variance (ANOVA).

\section{Determination of drug content and loading efficiency (LE\%)}

To determine the drug content, $10 \mathrm{mg}$ of microparticles were accurately weighed and dissolved in $10 \mathrm{~mL}$ of chloroform. The solution was diluted by a factor of 30 and the absorption band was determined by UV-Vis spectrophotometry (Perkin Elmer lambda 11/Bio spectrophotometer) at $327 \mathrm{~nm}$. The drug concentration was calculated from the calibration curve. The microsphere drug content was then estimated and expressed as mg \% 
Table 1. Independent variables and their levels investigated in the preparation of the PHB/PXC microparticles

\begin{tabular}{|c|c|c|c|}
\hline \multirow[t]{2}{*}{ Batch } & \multicolumn{2}{|c|}{ Internal phase } & \multirow{2}{*}{$\begin{array}{c}\text { External aqueous phase } \\
\text { Addition of isopropanol (C) }\end{array}$} \\
\hline & Organic solvent (A) & Volume (mL) (B) & \\
\hline 1 & chloroform (-) & $20(+)$ & no $(+)$ \\
\hline 2 & chloroform (-) & $5(-)$ & no $(+)$ \\
\hline 3 & chloroform (-) & $20(+)$ & yes $(-)$ \\
\hline 4 & chloroform (-) & $5(-)$ & yes $(-)$ \\
\hline 5 & dichloromethane $(+)$ & $20(+)$ & no $(+)$ \\
\hline 6 & dichloromethane $(+)$ & $5(-)$ & no $(+)$ \\
\hline 7 & dichloromethane $(+)$ & $20(+)$ & yes $(-)$ \\
\hline 8 & dichloromethane $(+)$ & $5(-)$ & yes $(-)$ \\
\hline
\end{tabular}

(-) low level; (+) high level.

(mg of drug per $100 \mathrm{mg}$ of microparticles). The loading efficiency was obtained using equation 1.

$$
L E \%=\frac{\text { drug found in microparticle }(\mathrm{mg})}{\text { drug initially added to the formulation }(\mathrm{mg})} \times 100
$$

\section{Scanning electron microscopy (SEM)}

To observe the internal structure of microparticles two different methods were used: $i$ ) frozen particles were cut with a blade, and ii) the particles were embedded in a glycerol polyglycidyl ether resin $\left(\mathrm{PELCO}^{\circledR}\right.$ Eponate 12$)$ and sectioned in a Leica ultramicrotome at $-70{ }^{\circ} \mathrm{C}$, using a diamond knife. The microtomed samples were carbon and gold coated by sputtering in a Bal-Tec MD 020 instrument (Balzers). The morphology of the particles was examined in a JSM-6340F field emission scanning electron microscope (JEOL Ltd.), operating at an accelerating voltage of $3 \mathrm{kV}$. The arithmetic mean diameter was determined of at least 300 particles measured on micrographs obtained by SEM.

\section{Thermal analysis}

DSC curves were obtained using a Shimadzu DSC-50 differential scanning calorimeter by heating from 25 to $220{ }^{\circ} \mathrm{C}$ at $10{ }^{\circ} \mathrm{C} \mathrm{min}-1$ in a nitrogen atmosphere $\left(50 \mathrm{~mL} \mathrm{~min}^{-1}\right)$.

\section{Pore size distribution}

The pore size distributions of the samples were determined from nitrogen adsorption/desorption isotherms obtained at the temperature of liquid nitrogen in an automated physisorption instrument (Autosorb-1-C, Quantachrome Instruments). Prior to the analysis, the samples were outgassed under vacuum at $473 \mathrm{~K}$ for $3 \mathrm{~h}$. Specific surface areas were calculated according to the Brunauer-EmmettTeller (BET) method, and the pore size distributions were obtained according to the Barret-Joyner-Hallenda (BJH) method from the adsorption data.

\section{$X$-ray powder diffraction analysis}

X-ray patterns were obtained using a Philips X'Pert $\mathrm{X}$-ray diffractometer. The incident radiation was $\mathrm{Cu} \mathrm{K}$ $(\lambda=1.5406 \AA)$ and the data were collected at $2 \theta$ from 5 to $35^{\circ}$.

\section{Molecular weight determination}

PHB molecular weight was determined by gel permeation chromatography (GPC) using a highperformance liquid chromatograph (Shimadzu 10 AD). The analysis was carried out using a Proge ${ }^{\circledR}$ TSK G4000 HXL column $(30 \mathrm{~cm} \times 7.8 \mathrm{~mm}$ ID; Supelco). The GPC system was eluted with chloroform at a flow rate of $0.8 \mathrm{~mL} \mathrm{~min}^{-1}$ at $35{ }^{\circ} \mathrm{C}$. Polystyrene was used as the molecular weight standard and the molecular weight of the samples was calculated based on the standard curve.

\section{In vitro drug release}

In vitro drug release studies were carried out in phosphate buffer solution (PBS) pH 7.4 at $37 \pm 0.5{ }^{\circ} \mathrm{C}$ under constant stirring (100 rpm). Microparticles $(n=3)$ containing $3 \mathrm{mg}$ of drug were placed into $200 \mathrm{~mL}$ of PBS and samples were withdrawn at regular time intervals. The samples were immediately returned to the dissolution vessels after analysis. The PXC concentration was measured by UV-Vis spectrophotometry, at $360 \mathrm{~nm}$. At the end of the assay, the microparticles were washed with distilled water, centrifuged, dried under vacuum and the pore size distribution and the molecular weight were determined as previous described.

\section{Results}

\section{Drug content and loading efficiency}

The loading efficiency and piroxicam content of the microparticles are presented in Table 2, where the batch 
number corresponds to the conditions indicated in Table 1. The results of the analysis of variance (Table 3) indicated that all the variables analyzed affect the PXC loading efficiency $\left(\mathrm{F}_{\mathrm{cal}}>\mathrm{F}_{\mathrm{tab}} ; \alpha=0.05\right)$.

The factorial design allowed the definition of the process conditions which lead to higher efficiencies for the loading of PXC into PHB microparticles. From the data shown in Table 2, the conditions used to obtain the microparticles of batches 2 and 7, denoted by M2 and M7, respectively, were selected. In spite of the higher loading efficiency values, the microparticles prepared using the conditions indicated for batches 4, 6 and 8 resulted in large aggregates (visualized by SEM) and, therefore, were excluded from further analysis.

Table 2. Loading efficiency and content of piroxicam in PHB microparticles

\begin{tabular}{lcc}
\hline Batch & Loading efficiency $(\%)$ & Drug content $(\mathrm{mg} \%)$ \\
\hline 1 & $10.6 \pm 1.8$ & $3.2 \pm 0.5$ \\
2 & $89.8 \pm 4.3$ & $25.8 \pm 1.2$ \\
3 & $10.0 \pm 1.8$ & $2.7 \pm 0.5$ \\
4 & $53.4 \pm 10.5$ & $15.4 \pm 3.1$ \\
5 & $5.5 \pm 3.3$ & $1.6 \pm 0.9$ \\
6 & $61.4 \pm 1.0$ & $19.9 \pm 0.2$ \\
7 & $57.7 \pm 2.4$ & $16.6 \pm 0.7$ \\
8 & $71.0 \pm 2.5$ & $21.4 \pm 0.5$ \\
\hline
\end{tabular}

Table 3. Summary of analysis of variance results obtained using loading efficiency as dependent variable

\begin{tabular}{lccc}
\hline & Sum of squares & Mean square & $\mathrm{F}$ \\
\hline $\mathrm{A}$ & 251.22 & 251.22 & $12.61^{*}$ \\
$\mathrm{~B}$ & 9235.21 & 9235.21 & $463.44^{*}$ \\
$\mathrm{C}$ & 152.52 & 152.52 & $7.65^{*}$ \\
Interaction AB & 742.56 & 742.56 & $37.26^{*}$ \\
Interaction AC & 2470.09 & 2470.09 & $123.95^{*}$ \\
Interaction BC & 1572.12 & 1572.12 & $78.89^{*}$ \\
Interaction ABC & 10.24 & 10.24 & 0.514 \\
Error & 159.42 & 19.93 & \\
Total & 14593.39 & & \\
\hline
\end{tabular}

A (type of organic solvent: dichloromethane or chloroform); B (volume of organic solvent: $5 \mathrm{~mL}$ or $20 \mathrm{~mL}$ ); $\mathrm{C}$ (addition of isopropanol to the aqueous external phase: yes or no). $\mathrm{F}_{\mathrm{tab}}(\mathrm{DF}=1 ; 8)=5.32(\alpha=0.05)$. *significance for $\alpha=0.05$.

\section{Characterization of selected microparticles}

\section{Morphological characteristics of microparticles}

Figure 1 shows SEM micrographs of the microparticles obtained using conditions of M2 and M7. The PHB/PXC microparticles (M7) had a spherical shape with an average diameter of $31.1 \pm 9.2 \mu \mathrm{m}$ and rough surface morphology. The inner part of these particles (Figure 1B) showed a predominance of the polymeric matrix in contrast with the microparticles obtained using the conditions of M2, which had hollow and irregular shaped particles with a large average size of $487 \pm 89 \mu \mathrm{m}$. From an analysis of the microparticle surfaces using a higher magnification, the PXC crystalline form at the surface of the M2 microparticles (Figure 1E) can be identified.
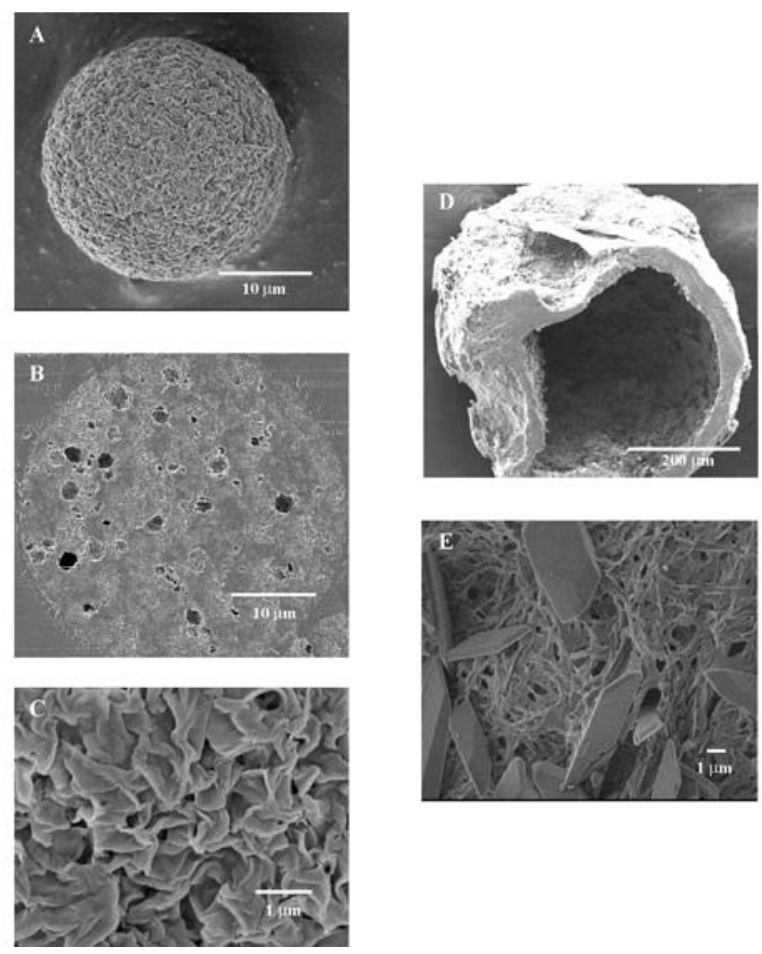

Figure 1. Scanning electron micrographs of PHB/PXC microparticles obtained through the procedure denoted as M7: (A) complete microparticle (B) inner part incorporated in a glycerol polyglycidyl ether resin, and (C) surface with higher magnification. Microparticles obtained using the conditions of M2: (D) fractured microparticle, and (E) surface.

Thermal analysis and X-ray powder diffraction analysis

The diffractogram of PXC maintained in aqueous medium for $24 \mathrm{~h}$ (Figure $2 \mathrm{~A}$ ) shows peaks at $2 \theta$ of $12.0^{\circ}$ and $26.5^{\circ}$ corresponding to those published in the literature for the monohydrate form. ${ }^{12}$ After the microencapsulation of the drug in the polymeric matrix, peaks corresponding to $\mathrm{PHB}$ at $2 \theta$ of $13.5^{\circ}$ and $16.9^{\circ}$ and peaks of PXC were observed in the X-ray pattern of microparticles prepared through the conditions of M2 and M7 (Figures 2C and 2D), indicating that both components of the microparticle are in a crystalline form. Figure 3 shows the DSC curves for PHB, piroxicam and polymer/drug microparticles obtained using the conditions of $\mathrm{M} 2$ and $\mathrm{M} 7$. The PHB shows two different melting temperatures at $166{ }^{\circ} \mathrm{C}$ and $176{ }^{\circ} \mathrm{C}\left(\Delta \mathrm{H}_{\mathrm{f}}=88 \mathrm{~J} \mathrm{~g}^{-1}\right)$, 

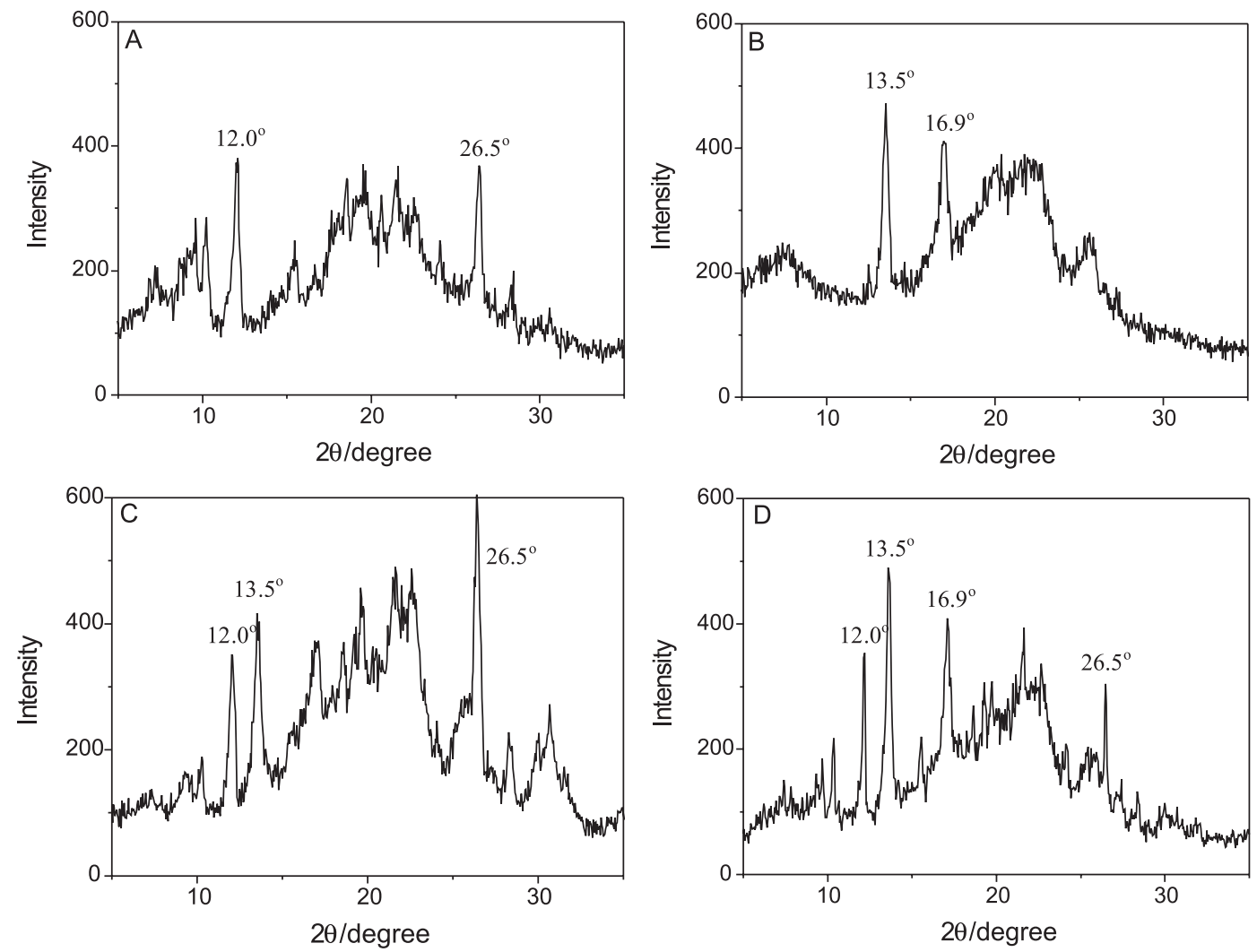

Figure 2. X-ray powder diffraction patterns for: (A) piroxicam (maintained in aqueous medium for 24 h); (B) PHB; (C) microparticles obtained under M2 conditions; (D) microparticles obtained under M7 conditions.
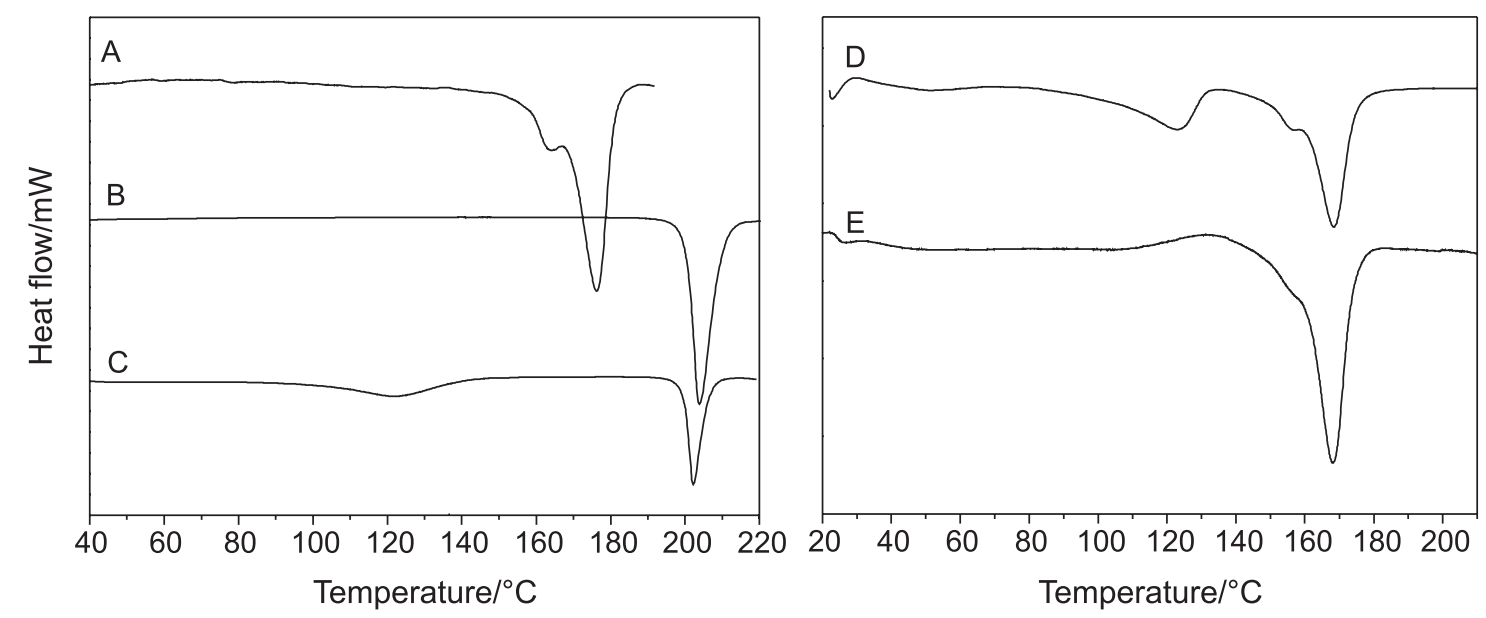

Figure 3. DSC curves of: (A) PHB; (B) piroxicam; (C) piroxicam (maintained in aqueous medium for 24 h); microparticles obtained using: (D) M2 conditions; (E) M7 conditions.

and PXC at $204{ }^{\circ} \mathrm{C}\left(\Delta \mathrm{H}_{\mathrm{f}}=101 \mathrm{~J} \mathrm{~g} \mathrm{~g}^{-1}\right)$. However, when PXC was maintained in aqueous medium for $24 \mathrm{~h}$ a peak at $122{ }^{\circ} \mathrm{C}$, corresponding to dehydratation, was observed, indicating the presence of PXC in the monohydrate form, in agreement with the X-ray diffraction analysis and data from different polymorphic forms of piroxicam described in the literature. ${ }^{12}$ This peak can be observed in the DSC curve of the microparticles prepared using M2 conditions. One interesting point that can be evaluated from the DSC curves for the microparticles prepared using the two conditions is the enthalpy of fusion value $\left(\Delta \mathrm{H}_{\mathrm{f}}=91 \mathrm{~J} \mathrm{~g} \mathrm{~g}^{-1}\right)$ which corresponds to the sum of the enthalpy of fusion values for the undiluted components, considering the percentage in the microparticle composition. In the DSC curves of the microparticles, only one melting peak, at $168^{\circ} \mathrm{C}$, can be observed. This suggests that PHB and PXC are melting at the same temperature. 


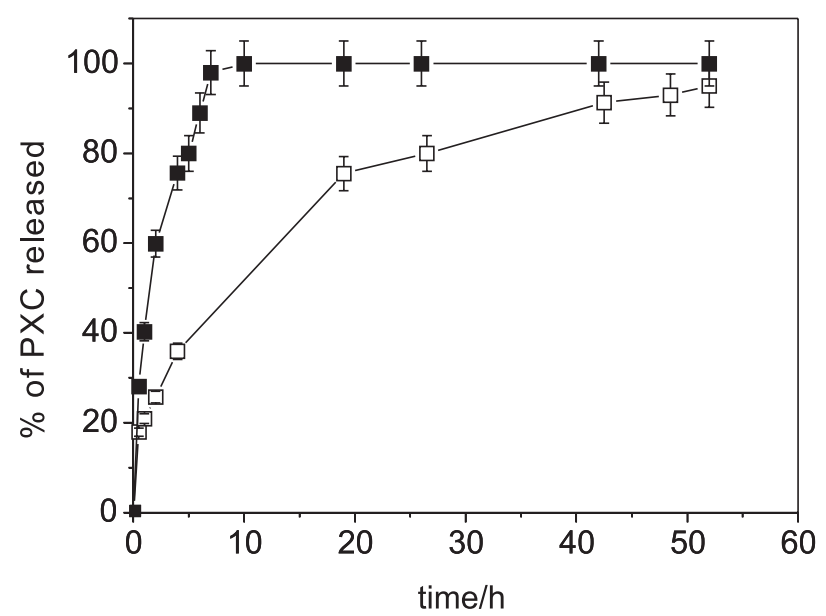

Figure 4. Release profiles of PXC from microparticles obtained under: ( $)$ M2 and ( $\square$ ) M7 conditions, in phosphate buffer $\mathrm{pH}$ 7.4.

\section{In vitro drug release}

The release profiles of PXC from the PHB microparticles are shown in Figure 4. After $8 \mathrm{~h}$ and $50 \mathrm{~h}$, the total amount of the encapsulated drug was released from the M2 and M7 microparticles, respectively.

Figure 5 shows the pore size distribution curves obtained through both procedures M2 and M7, before and after drug release. The pores are smaller than those of the rough texture observed in Figure 1. The pore size is related to the kinetics of the evaporation process of the organic solvent in the internal phase. The fast extraction of the dichloromethane occurred when isopropanol was added to the external phase (M7), originating the pores in the polymeric matrix. Also, the fast rate of PHB crystallization may contribute to the formation of a rough and porous polymeric matrix. ${ }^{11-13}$ After the release of the drug, the morphology of the microparticles had the same characteristics (visualized by
SEM; micrographs not shown), the molecular weight of PHB remained unchanged and pores sizes between 40 and $100 \AA$ appear, as shown in Figure 5 (B and D), suggesting that the drug release occurred mainly through the desorption of the PXC from the microparticle surfaces (in the case of M2) and its diffusion through the matrix pores formed during the preparation of the particles and also the pores formed due to the drug solubilization in the dissolution medium (in the case of M7).

\section{Discussion}

The oil-in-water emulsion solvent evaporation technique was used, in this study, to prepare PHB microparticles containing piroxicam as the drug model. It is well known that the modification of the processing conditions can affect the characteristics of microparticles prepared by this technique. The factorial design employed in this study showed that the type and the volume of the organic solvent of the internal phase and the addition of isopropanol to the aqueous external phase influence the PXC loading into PHB microparticles. These processing conditions must be controlled to obtain microparticles with high efficiencies of drug loading. The value of least significant difference obtained through application of the Tukey test was 17.74 . When this value was used to compare the LE\% values given in Table 2, it was found that the increase in the organic solvent volume from $5 \mathrm{~mL}$ to $20 \mathrm{~mL}$ led to a significant decrease in the PXC loading efficiency, except when dichloromethane was used as the internal phase and isopropanol was added to the external aqueous phase (batch 7). In this case, the addition of isopropanol enhances the solubility of dichloromethane in the aqueous phase, promoting its extraction and allowing the solidification of the microspheres. ${ }^{14}$ The faster elimination of
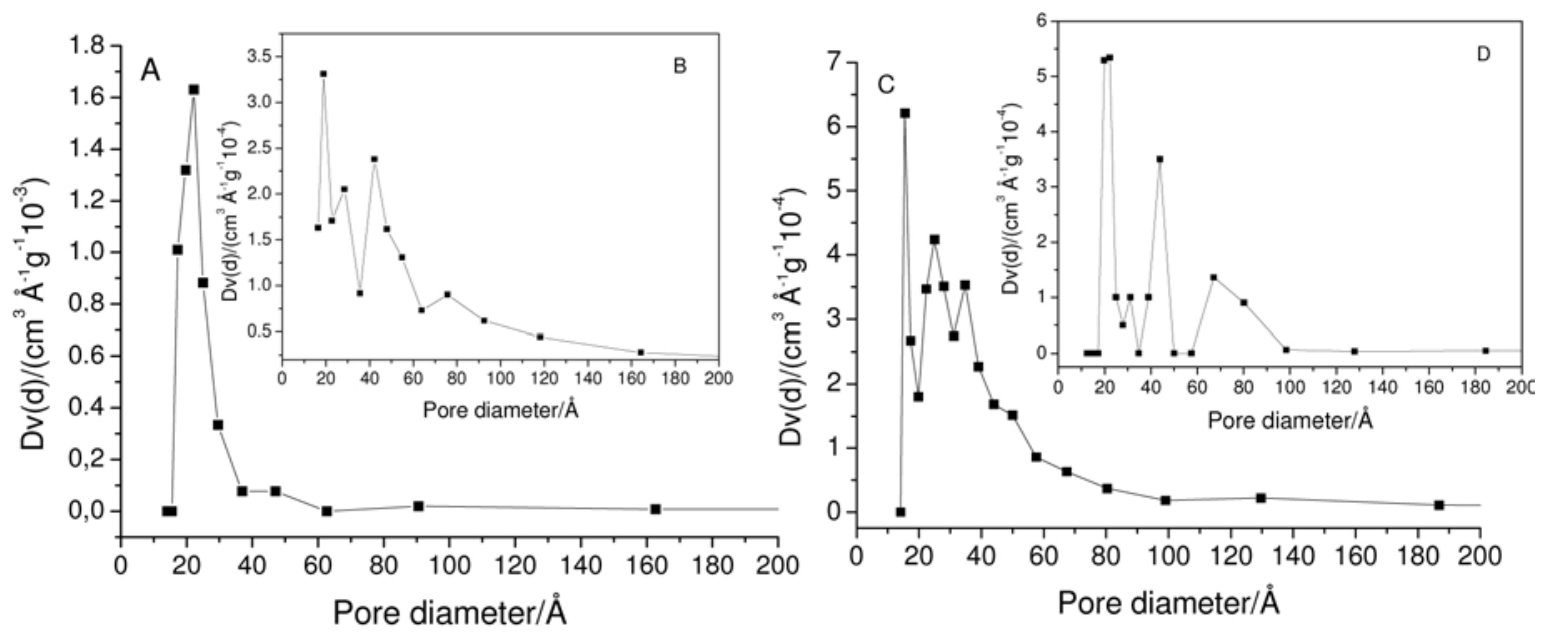

Figure 5. Pore diameter distribution curves, based on the BJH method: (A) M2 microparticles; (B) M2 microparticles after 8 h in phosphate buffer $\mathrm{pH} 7.4$; (C) microparticles M7; (D) microparticles after $50 \mathrm{~h}$ in phosphate buffer $\mathrm{pH} 7.4$. 
the organic solvent, therefore, contributed to the acceleration of the formation of the particles and, in turn, allowed the entrapment of the piroxicam in the microspheres.

The processing conditions also influenced the size and morphological characteristics of the microparticles, as can bee seen in Figure 1. The differences in the mean size of the microparticles obtained using the two selected conditions (M2 and M7) may be associated with the PHB concentration in the organic phase. When using a small volume of organic solvent as the internal phase (M2), the polymer/drug solution becomes more viscous and, consequently, more resistant to fragmentation into small droplets which, in turn, leads to the generation of a coarser emulsion and, subsequently, to the formation of larger microspheres. ${ }^{15}$

DSC and X-ray powder diffraction analysis were used, in this study, to evaluate changes in the polymorphic forms of PXC during the microencapsulation process. Piroxicam shows polymorphism, occurring in three main forms: $\alpha$ (needle), $\beta$ (cubic) and one monohydrate form. ${ }^{12,16}$ Solvent polarity and crystallization kinetics are critical parameters for the crystallization of PXC in each polymorphic form. ${ }^{12,17}$ The results obtained showed the presence of PXC in the monohydrate form in both microparticles (M2 and M7). The conversion to this form occurred due to the contact of the drug with the aqueous medium during the microencapsulation process.

A variety of factors can affect drug release from polymeric microparticles and some of these factors, such as microparticle size and drug distribution within the polymeric matrix, are related to the processing conditions used to prepare the microparticles. Generally, the smaller the mean particle diameter, the shorter the diffusion path for drug releases, and consequently, the faster the release rate. ${ }^{18}$ However, in this study, the largest microparticles (M2) released the PXC more rapidly, due to the presence of drug crystals on the microparticle surfaces and to the hollow structure of these particles. The surface localization of the drug explains the rapid initial drug release and short duration of release from the microparticles. The microspheres obtained using the M7 conditions were found to somewhat control the PXC release, which is associated with the dense matrix in the inner microparticle and to the location of the drug, preferentially, inside of the particles, which, in turn, is a result of the faster extraction of the organic solvent from the internal phase of the emulsion due to the addition of isopropanol. A fast rate of solvent removal can contribute to a heterogeneous distribution of drug within the internal phase as it hardens. ${ }^{15}$

The release of a drug from polymeric microparticles occurs through different mechanisms: desorption of the drug from the surface of the particles; diffusion of the drug through the pores of the polymeric matrix; erosion of the polymeric matrix; polymer degradation or a combination of different processes. ${ }^{5,19}$ As PHB is very slowly degraded, the release profile of a drug from a PHB matrix is generally dependent on drug diffusion rather than on polymer degradation..$^{20}$ The results for the PHB molecular weight, pore size distributions and the morphology of the microparticles after the release assay indicated that the release of PXC from PHB microparticles occurs mainly through the two mechanisms: desorption of the drug from the surface of the particles and diffusion of the drug through the pores of the polymeric matrix.

\section{Conclusions}

The results demonstrated that the process conditions used to prepare PHB/PXC microparticles influence its morphological characteristics, loading efficiency and drug release, indicating that it is possible to obtain microparticles with specific characteristics through the optimization of the process parameters. Using the M2 conditions it was possible to obtain microparticles with high efficiencies of PXC loading, but the presence of drug crystals on the surface leads to almost immediate release. On the other hand, the microparticles obtained using the M7 conditions had the desired size and morphological characteristics for intraarticular or intramuscular administration, indicating that these microparticles can be considered as a promising system to control drug release.

\section{References}

1. Pouton, C. W.; Akhtar, S.; Adv. Drug Delivery Rev. 1996, 18, 133.

2. Freier, T.; Kunze, C.; Nischan, C.; Kramer, S.; Sternberg, K.; Sab, M.; Hopt, U. T.; Schmitz, K. P.; Biomaterials 2002, 23, 2469.

3. Chen, G. Q.; Wu, Q.; Biomaterials 2005, 26, 6565.

4. O’Donnell, P. B.; McGinity, J. W.; Adv. Drug Delivery Rev. 1997, 28, 25.

5. Freiberg, S.; Zhu, X. X.; Int. J. Pharm. 2004, 282, 1.

6. Freitas, S.; Erkle, H. P.; Gander, B.; J. Controlled Release 2005, 102,313

7. Mateovic, T.; Kriznar, B.; Bogataj, M.; Mrhar, A.; J. Microencapsulation 2002, 19, 29.

8. Joseph, N. J.; Lakshmi, S.; Jayakrisshnan, A.; J. Controlled Release 2002, 79, 71.

9. Polauff, E. J.; Kim, K. K.; Pack, D. W.; J. Pharm. Sci. 2005, 94, 2013.

10. Fernández-Carballido, A.; Herrero-Vanrell, R.; MolinaMartínez, I. T.; Pastoriza, P.; Int. J. Pharm. 2004, 279, 33. 
11. Martin, M. A.; Miguens, F. C.; Rieumont, J.; Sanchez, R.; Colloids Surf., B 2000, 17, 111.

12. Vrečer, F.; Vrbinc, M.; Meden, A.; Int. J. Pharm. 2003, 256, 3.

13. Kai, Z.; Ying, D.; Chen, G. Q.; Biochem. Eng. J. 2003, 16, 115 .

14. Meng, F. T.; Ma, G. H.; Liu, Y. D.; Qiu, W.; Su, Z. G.; Colloids Surf., B 2004, 33, 177.

15. Thompson, C. J.; Hansford, D.; Higgins, S.; Rostron, C.; Hutcheon, G. A.; Munday, D. L.; Int. J. Pharm. 2007, 329, 53

16. Bertoluzza, A.; Rossi, M.; Taddei, P.; Redenti, E.; Zanol, M.; Ventura, P.; J. Mol. Struct. 1999, 480-481, 535.
17. Taddei, P.; Torreggiani, A.; Simoni, R.; Biopolymers 2001, 62, 68

18. Berkland, C.; Kipper, M. J.; Narasimhan, B.; Kim, K.; Pack, D. W.; J. Controlled Release 2004, 94, 129.

19. Schaffazick, S. R.; Guterres, S. S.; Quim. Nova 2003, 26, 726.

20. Wang, Y.; Wang, X.; Wei, K.; Zhao, N.; Zhang, S.; Chen, J.; Mater. Lett. 2007, 61, 1071.

Received: September 14, 2007 Web Release Date: April 23, 2008

FAPESP helped in meeting the publication costs of this article. 